\title{
Effects of Ficus umbellata (Moraceae) Aqueous Extract and 7-Methoxycoumarin on Scopolamine-Induced Spatial Memory Impairment in Ovariectomized Wistar Rats
}

\author{
Stéphane Zingue $\mathbb{D}^{1},{ }^{1,2}$ Harquin Simplice Foyet $\mathbb{D}^{\mathbb{D}},{ }^{3}$ Sefirin Djiogue $\mathbb{D}^{\mathrm{D}},{ }^{2}$ Yannick Ezo'o Ezo'o, \\ Hervé Hervé Ngatanko Abaïssou, ${ }^{2}$ Pafroumi Fachagbo, ${ }^{1}$ and Dieudonné Njamen $\mathbb{D}^{2,3}$ \\ ${ }^{1}$ Department of Life and Earth Sciences, Higher Teachers' Training College, University of Maroua, P.O. Box 55, Maroua, Cameroon \\ ${ }^{2}$ Department of Animal Biology and Physiology, Faculty of Science, University of Yaoundé 1, P.O. Box 812, Yaoundé, Cameroon \\ ${ }^{3}$ Department of Biological Sciences, Faculty of Science, University of Maroua, P.O. Box: 814, Maroua, Cameroon
}

Correspondence should be addressed to Stéphane Zingue; stephanezingue@gmail.com and Dieudonné Njamen; dnjamen@gmail.com

Received 10 September 2017; Accepted 10 July 2018; Published 30 September 2018

Academic Editor: Jesus Pastor

Copyright (c) 2018 Stéphane Zingue et al. This is an open access article distributed under the Creative Commons Attribution License, which permits unrestricted use, distribution, and reproduction in any medium, provided the original work is properly cited.

\begin{abstract}
The present work was undertaken to evaluate the ability of F. umbellata aqueous extract and its major component 7 methoxycoumarin (MC) to improve scopolamine-induced spatial memory impairment in ovariectomized Wistar rats. For this to be done, 10 sham-operated and 30 postmenopausal-like rats were randomly distributed in eight groups $(n=5)$ and treated with distilled water $(2 \mathrm{~mL} / 250 \mathrm{~g})$, estradiol valerate $(1 \mathrm{mg} / \mathrm{kg} \mathrm{BW})$, piracetam $(1.5 \mathrm{mg} / \mathrm{kg} \mathrm{BW})$, $F$. umbellata aqueous extract (50 and $200 \mathrm{mg} / \mathrm{kg} \mathrm{BW})$, or MC (1 mg/kg BW) for 21 consecutive days. Before and after the memory impairment with scopolamine $(2 \mathrm{mg} / \mathrm{kg} \mathrm{BW})$, animals underwent behavioral evaluations on Y- and radial mazes. As results, age and ovariectomy did not induce significant changes in the reference memory errors. While age decreased working memory errors, ovariectomy increased it. The MC as well as $F$. umbellata extract significantly increased $(p<0.01)$ the percentage of spontaneous alternation and decreased $(p<0.001)$ working and spatial reference memory errors and anxiety parameters (rearing and grooming) in ovariectomized rats. MC significantly reduced $(p<0.05)$ the MDA level, but resulted in an increase in GSH level in brain homogenates. These results suggest that MC is endowed with neuroprotective effects and could account for the neuroprotective effects of F. umbellata in rats.
\end{abstract}

\section{Introduction}

Estrogens are steroidal hormones mainly produced by ovaries, which greatly fluctuate during women's lifespan and decline with menopause [1]. Numerous studies indicate that estrogens have neuroprotective effects either by direct activation of estrogen receptors (ERs), which are located in the brain, or by activation of receptors of other neuroprotective factors [1]. Studies in female rodents have shown that a decrease in plasmatic estrogen levels following ovariectomy enhances brain damage under neurodegenerative conditions $[2,3]$ and increases amyloid- $\beta$ oligomers in a mouse model of Alzheimer's disease (AD) [4]. AD is the most frequent form of dementia and is an age-related neurodegenerative disease characterized by a loss or decline in memory and severe cognitive as well as behavioral impairments [5]. According to the World Alzheimer Report [6], 46.8 million people worldwide have dementia, out of which 60 to $70 \%$ are $\mathrm{AD}$ patients. To date, the pathophysiology of $\mathrm{AD}$ remains unclear, but it is considered that the $\beta$-amyloid and tau protein aggregation, reduced acetylcholine (ACh), and glutamatergic deficit are principal agents of the pathogenesis of $\mathrm{AD}$ [7]. However, age, genetic predisposition, stress, emotions, and the sudden drop in estrogen levels after menopause are nowadays recognized as risk factors that may contribute to $\mathrm{AD}$ symptoms $[8,9]$. 
Hormone replacement therapy (HRT) has been used for many years to treat symptoms of menopause, including hot flushes and depression. Prospective studies have shown that it enhances cognitive skills in postmenopausal women [10]. Nevertheless, a long-term use of HRT is associated with adverse effects such as increased risks of endometrial and breast cancers, stroke, and pulmonary thromboembolism [11-13]. Hence, many women resort to natural health remedies as alternative therapies to treat menopausal symptoms [14]. Plant preparations and plant-derived compounds (phytoestrogens) are being considered as natural alternative to hormone replacement therapy.

Ficus umbellata (Moraceae) is a tropical tree commonly called "Mewed" in "Guiziga." Its back is used in indigenous medicine for the treatment of menopause-related physiological disorders [15]. Just like F. sur, F. platyphylla, F. ovata, F. ingens, and F. glumosa, it is used to treat some nervous system disorders such as dementia, neuralgia, and epilepsy [15, 16]. Previous studies revealed the transactivation of ER $\alpha$ in a reporter gene assay induces significant estrogen-like effects on estrogen target organs (uterus, vagina, and mammary gland) in rats when treated with F. umbellata aqueous and methanol extracts. These extracts also brought about a significant decrease in the frequency of occurrence of hot flushes in experimental rats. The major component of these extracts after isolation and characterization was found to be 7methoxycoumarin (MC) [17]. Additionally, MC exhibited estrogen-like and tissue-selective effects in vitro on cellbased assay and in vivo on Wistar rats [18]. In the present study, the neuroprotective potential of MC as well as F. umbellata aqueous extract was evaluated using scopolamineinduced spatial memory impairment in ovariectomized Wistar rats. The investigation focused on number of entries, the percentage of spontaneous alternation, and working and spatial reference memory errors. Since scopolamine-induced memory deficits are accompanied with oxidative damage, oxidative stress biomarkers (MDA and GSH levels) were also assessed.

\section{Materials and Methods}

2.1. Chemicals. Estradiol valerate (Progynova ${ }^{\circledR} 2 \mathrm{mg}$ ) was purchased from Delpharm (Lille, France). UPLC-grade solvents methanol, acetonitrile $(\mathrm{ACN})$, methyl tert-butyl ether (MTBE), water, scopolamine, piracetam, and formic acid (FA) were purchased from Sigma-Aldrich (Saint-QuentinFallavier, France). Penicillin (xtapen ${ }^{\circledR}$ ) was provided by CSPC Zhongnuo Pharmaceutical (Shijiazhuang City, China). Diclofenac $\left(\right.$ Dicloecnu $\left.^{\circledR}\right)$ was provided by ECNU Pharmaceutical (Yanzhou City, China).

2.2. Plant Material and Preparation of F. umbellata Extracts. Stem bark of F. umbellata was harvested in Yaounde (centre region, Cameroon) in September 2013. This botanical sample was authenticated by Mister Victor Nana, botanist at the National Herbarium of Cameroon (HNC) by comparison to the specimens deposited under the voucher number 99/HNC. After shade drying and grinding, $2000 \mathrm{~g}$ of powder was macerated in water at room temperature $(5 \mathrm{~L}$ of solvent $\times 3,48 \mathrm{~h}$ per extraction). The combined solutions were filtered with Whatman paper number 4 and evaporated using an oven with ventilation $\left(40^{\circ} \mathrm{C}\right.$, during $\left.48 \mathrm{~h}\right)$ to yield $229.8 \mathrm{~g}$ of aqueous crude extract. Alternatively, $2700 \mathrm{~g}$ of the powder was macerated in $95 \%$ methanol at room temperature (5 $\mathrm{L}$ of solvent $\times 3,48 \mathrm{~h}$ per extraction). The combined solutions were evaporated under reduced pressure (337 mbar at $40^{\circ} \mathrm{C}$ ) using a rotary evaporator to yield $162 \mathrm{~g}$ of a methanol crude extract $(\mathrm{MeOH})$.

2.3. Isolation of 7-Methoxycoumarin (MC). UPLC chromatograms of F. umbellata aqueous as methanol extracts showed that MC is their major compound (Supplementary Data 1). After a bioguided fractionation of $F$. umbellata methanol extract, MC was isolated [17]. Figure 1 shows a summary of the physicochemical properties of MC.

2.4. Animals. Healthy young female Wistar rats aged four weeks, weighing $(\sim 150 \mathrm{~g})$, were used in this study. These rats were purchased from the breeding facility of the Animal Physiology Laboratory of the University of Yaounde I (Cameroon). Animals were housed in clean polyacrylic cages in a lightcontrolled room (approx. $12 \mathrm{~h}$ light/dark), and temperature was maintained around $25^{\circ} \mathrm{C}$. A soy-free rat chow diet was provided to the animals with water ad libitum. The composition of animal diet was as follows: corn (36.7\%), bone flour (14.5\%), wheat $(36.6 \%)$, fish flour $(4.8 \%)$, crushed palm kernel $(7.3 \%)$, sodium chloride $(0.3 \%)$, and vitamin complex (Olivitazol ${ }^{\circledR} 0.01 \%$ ). Housing of animals and all experiments were conducted in accordance with the principles and procedures of the European Union legislation on the use of animals for scientific purposes (Directive 2010/63/EU) adopted by the Cameroon Institutional National Ethic Committee, Ministry of Scientific Research and Technology Innovation (reg. number FWA-IRD 0001954).

2.5. Study Design. At the beginning of the experiment, 5 rats aged 2.5 months underwent behavioral evaluations on $\mathrm{Y}$ - and radial mazes in order to record basic data (BD). Afterwards, ketamine $(50 \mathrm{mg} / \mathrm{kg} \mathrm{BW}$; ip) and diazepam $(10 \mathrm{mg} / \mathrm{kg} \mathrm{BW}$; ip) anesthesia were used. 30 rats were bilaterally ovariectomized using the dorsal approach, and 10 others were shamoperated. Animals were allowed for (84) days for the setup of menopausal-like conditions [19-21], followed by the random distribution of animals (now aged 5.5 months) into eight groups $(n=5)$. Groups I (SHAM 1) and II (SHAM 2) were sham-operated rats and received distilled water. Groups III to VIII were ovariectomized rats treated as follows: Group III received distilled water and served as negative control (OVX). Group IV served as positive control 1 and received estradiol valerate $(1 \mathrm{mg} / \mathrm{kg} \mathrm{BW})$. Group V served as positive control 2 and received piracetam, a nootropic drug that exhibits cognition-enhancing properties [22] at a dose of $1.5 \mathrm{mg} / \mathrm{kg}$ BW. Groups VI and VII received the F. umbellata aqueous extract at the doses of 50 and $200 \mathrm{mg} / \mathrm{kg}$, respectively. Group VIII received the MC at the dose of $1 \mathrm{mg} / \mathrm{kg}$. Distilled water was used as a vehicle for the dissolution of substances which were administered orally using a feeding tube $(2 \mathrm{~mL} / 250 \mathrm{~g})$ for three weeks (a single dose per day). 


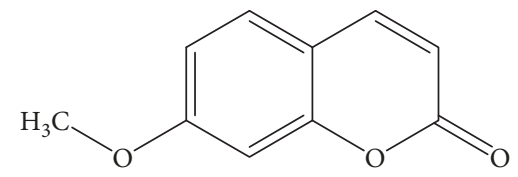

FIgURE 1: 7-Methoxycoumarin (molecular weight $=176.1 \mathrm{M}$; molecular formula $=\mathrm{C}_{10} \mathrm{H}_{8} \mathrm{O}_{3}$ ) [17].

Piracetam and MC were given intraperitoneally $(0.3 \mathrm{~mL} /$ $250 \mathrm{~g}$ ). However, parallel injections/gavages of vehicle were given so that all rats had the same administration experiences. Behavioral testing was achieved between the 12th and 21st days of treatment. On the last day of treatment, scopolamine $(2 \mathrm{mg} / \mathrm{kg})$ was administered as a single dose $30 \mathrm{~min}$ after drug administration through intraperitoneal (ip) injection route to all the groups except group I (SHAM 1). Exceptionally this day, behavioral testing was done before and after scopolamine injection. A right hemisphere of each animal's brain was homogenized to give 20\% $(w / v)$ homogenate in an ice-cold sodium buffer $(0.1 \mathrm{M}, \mathrm{pH} 7.3)$. The homogenate was centrifuged at $3000 \times \mathrm{g}$ for $15 \mathrm{~min}$ at $4^{\circ} \mathrm{C}$. The supernatant was stored at $-20^{\circ} \mathrm{C}$ for the determination of some oxidative stress biomarkers.

\subsection{Behavioral Testing}

2.6.1. Y-Maze Test. Short-term memory was assessed by spontaneous alternation behavior in the Y-maze task as previously reported by Foyet et al. [23]. Briefly, the maze consisted of three arms ( $35 \mathrm{~cm}$ long, $25 \mathrm{~cm}$ high, and $10 \mathrm{~cm}$ wide) and an equilateral triangular central area. Each rat was placed in a randomized order at the end of one arm and allowed to move freely through the maze for $8 \mathrm{~min}$. An arm entry was counted when the hind paws of the rat were completely within the arm. Spontaneous alternation behavior was defined as three consecutive entries in three different arms (i.e., A, B, C or B, C, A, etc.). The percentage alternation score (PAS) was calculated by the following formula: $\mathrm{PAS}=$ [total alternation number/ (total number of entr ies -2$)] \times 100$. Furthermore, the total number of arm entries was used as a measure of general activity of the animals. The maze was wiped clean with $70 \%$ ethanol between each animal to minimize odor cues [23, 24].

Anxiety negatively influences learning activity and new information storage; some anxiety parameters such as frequency of rearing and grooming [25] were therefore recorded during the Y-maze test.

2.6.2. Radial Arm Maze. In this study, the radial arm maize was used to assess working memory and reference memory as previously reported by Hritcu et al. [26]. This apparatus was a wooden platform raised $50 \mathrm{~cm}$ above the floor, consisting of 8 arms ( $48 \mathrm{~cm}$ long $\times 12 \mathrm{~cm}$ wide). All the arms numbered 1-8 extended radially from a central area $(32 \mathrm{~cm}$ in diameter). A food cup containing a single $50 \mathrm{mg}$ food pellet was placed at the end of each arm. Visual cues were placed around the maze and maintained in their positions throughout the testing period. In order to maintain at $85 \%$ of their free feeding weight, the animals were kept on restricted diet over a week prior to the performance of the maze task with free access to water ad libitum. Before the trial training for recording sequences of alternation in the radial maze arms, three rats were placed in the central platform of the radial maze and allowed to explore freely and consume the food distributed on the central platform and arms. The food was progressively restricted to the arms and the food cups. During the trial training, a rat is placed on the central platform and allowed to explore until all the 5 baits had been consumed or until 5 minutes has elapsed. During the eight-day tests, each animal is placed individually on the central platform of the radial maze facing an arm for the assessment of reference memory and working memory. Five arms (numbers $1,2,4,5$, and 7) out of 8 were baited throughout the training days. The number of reference memory errors (entering an arm that was not baited) and working memory errors (entering an arm containing food, but previously entered) was measured. An arm entry was counted when all the four limbs of the animal were within the arm. $70 \%$ ethanol was used to clean the maze after the passage of each rat in order to reduce residual odors $[26,27]$.

2.7. Histological Analysis. The histomorphology of the brain was performed from $5 \mu \mathrm{m}$ sections of paraffin-embedded tissues following hematoxylin-eosin staining. Brains were photographed at 40x magnification using the complete Zeiss equipment consisting of a microscope Axioskop 40 connected to a computer where the image was transferred, and analyzed with the MRGrab1.0 and AxioVision 3.1 software, all provided by Zeiss (Hallbergmoos, Germany).

\subsection{Biochemical Analysis}

2.8.1. Total Content of Reduced Glutathione GSH. To measure the reduced glutathione (GSH) level, the brain homogenate in sodium buffer $(0.1 \mathrm{M}, \mathrm{pH} 7.3)$ was taken. The procedure was followed as previously described by Shamnas et al. [28]. Briefly, the homogenate was mixed with an equal volume of trichloroacetic acid (TBA, 20\%) containing $1 \mathrm{mM}$ EDTA to precipitate the proteins. The mixture was allowed to stand for 5 minutes prior to centrifugation. The supernatant $(200 \mu \mathrm{L})$ was then transferred to a new set of test tubes to which was each added $1.8 \mathrm{~mL}$ of Ellman's reagent (5, $5^{\prime}$-dithiobis-2-nitrobenzoic acid) $(0.1 \mathrm{mM})$ prepared in $0.3 \mathrm{M}$ phosphate buffer with $1 \%$ sodium citrate solution. Then, the content in all the test tubes was made up to the volume of $2 \mathrm{~mL}$ with distilled water. After the completion of the total reaction, the solutions were measured at $412 \mathrm{~nm}$ against a blank. Absorbance values were then compared with a standard curve generated from GSH.

2.8.2. Determination of MDA Level. Malondialdehyde (MDA), which is a measure of lipid peroxidation, was spectrophotometrically measured using the thiobarbituric acid assay as reported by Padurariu et al. [29]. Briefly, $200 \mu \mathrm{L}$ of brain homogenate was added and mixed with $1 \mathrm{~mL}$ of $50 \%$ trichloroacetic acid in $0.1 \mathrm{M} \mathrm{HCl}$ and $1 \mathrm{~mL}$ of $26 \mathrm{mM}$ thiobarbituric acid. After vortex mixing, samples were maintained at $95^{\circ} \mathrm{C}$ for 20 minutes. Furthermore, samples were centrifuged at $800 \times \mathrm{g}$ for 10 minutes and supernatants were 
read at $532 \mathrm{~nm}$. A calibration curve was constructed using MDA as standard, and the results were expressed as mM/ mg protein.

2.9. Statistical Analysis. Results were presented as means $\pm s$ tandard error of the mean (SEM). All formula and functions were calculated with Microsoft Excel software. Data analysis was performed with GraphPad Prism 5.0 software. The normal distribution of data was assessed by Shapiro-Wilk test, and the distribution was found normal $(p=0.5)$. Further, the one-way ANOVA test was followed by the NewmanKeuls post hoc test; a stepwise multiple comparison procedure was used to identify sample means that are significantly different from each other. Differences were considered significant at a probability level of $5 \%(p<0.05)$.

\section{Results}

3.1. Effect of Age and Ovariectomy on Short-Term and LongTerm Memories. As observed in Figure 2, age has no effect on number of entries (Figure 2(a)) in the Y-maze. Indeed, no significant change was noted in normal rats aged 5.5 months (SHAM 1) as compared to the basic data (BD) recorded in youngest animal (2.5 months). Figure 2(b) shows that the percentage of spontaneous alternation behavior significantly $(p<0.001)$ increased with age. Furthermore, ovariectomy significantly $(p<0.001)$ increased the number of entries (Figure $2(a))$ but significantly $(p<0.05)$ reduced the percentage of spontaneous alternation as compared to the agematched normal animal (SHAM 1).

Age and ovariectomy did not induce significant changes in the reference memory errors (Figure 2(d)), while normal rats aged 5.5 months made less working memory errors than the youngest ones did (2.5 months), although significant $(p<0.01)$ only on day 1 of the experiment (Figure 2(c)). The ovariectomized rats made more working memory errors as compared to the age-matched normal rats (Figure 2(c)). Interestingly, the ovariectomized rats took a significantly $(p<0.001)$ lower time to collect baits as compared to the normal group (Figure 2(e)). It is worth noting that working memory error and reference memory error as well as the time taken to collect all baits decreased continuously throughout the experiment in all groups.

3.2. Effect of Age and Ovariectomy on Anxiety Parameters. The number of rearing and grooming significantly $(p<0.001)$ decreased in normal rats aged 5.5 months as compared to youngest rats (2.5 months) (Figure 3$)$. Ovariectomy significantly $(p<0.001)$ increased these parameters as compared to aged-matched normal rats (SHAM 1).

3.3. Effects of 7-Methoxycoumarin and F. umbellata Extract on Short-Term Memory. Before memory impairment with scopolamine, ovariectomized rats (OVX) had a significantly higher $(p<0.001)$ number of entries into the arms of the Ymaze than normal rats (SHAM 2). F. umbellata aqueous extract treatment at both doses $(50$ and $200 \mathrm{mg} / \mathrm{kg})$ significantly $(p<0.001)$ reduced this parameter just like piracetam $(1.5 \mathrm{mg} / \mathrm{kg}$ ) as compared to the OVX group (Figure 4(a)). Thirty minutes after injection of scopolamine, the number of entries significantly $(p<0.001)$ increased in normal rats treated with scopolamine (SHAM $2+$ SCOP) as compared to the age-matched normal group, which did not receive scopolamine (SHAM 1). No significant change was observed between all animals to which scopolamine was administered (Figure 4(b)).

Figure 4(c) shows a nonsignificant decrease in the percentage of spontaneous alternations behavior with ovariectomy before the administration of scopolamine. There was a nonsignificant increase in this parameter in all OVX rats treated with different substances (except with FU 200). After memory impairment (Figure 4(d)), a significant decrease in the spontaneous alternations was observed in normal rats (SHAM $2+$ SCOP) as well as in ovariectomized rats $(\mathrm{OVX}+\mathrm{SCOP})$ as compared to the age-matched normal rats (SHAM 1). Apart from the $50 \mathrm{mg} / \mathrm{kg}$ dose of F. umbellata aqueous extract, all treatments induced a significant increase in the percentage of spontaneous alternations as compared to ovariectomized rats (OVX + SCOP).

3.4. Effect of 7-Methoxycoumarin and F. umbellata Extract on Long-Term Memory. The radial arm maze test was performed for 8 days, from the 14th to the 21st days of treatment. It was noted that before the scopolamine-induced memory impairment, the ovariectomized rats (OVX) showed more working (Figure 5(a)) and spatial reference memory (Figure 5(b)) errors as compared to normal rats (SHAM 2), but the difference was not statistically significant. After scopolamine administration, normal (SHAM 2) and ovariectomized rats displayed more $(p<0.001)$ working and spatial reference memory errors as compared to normal rats, which did not receive scopolamine (SHAM 1). The ovariectomized rats treated with $F$. umbellata aqueous extract (50 and $200 \mathrm{mg} / \mathrm{kg})$ as well as MC (1 mg/kg) showed a significant $(p<0.001)$ reduction of working memory and spatial reference memory errors as compared to the OVX group.

The variations of the scanning time in the radial maze with different groups are depicted in Figure 5(c). It can be observed that ovariectomized rats (OVX) are faster in the radial arm maze before scopolamine injection as compared to all other groups. Moreover, the time required to collect all the baits in the radial arm maze gradually decreased from day 1 to day 7 in rats treated with the $F$. umbellata aqueous extract at both doses as well as with MC. Scopolamine administration on day 8 significantly $(p<0.01)$ increased the time taken to collect all baits by ovariectomized (OVX + SCOP) and normal (SHAM 2+SCOP) rats as compared to the normal control group (SHAM 1). However, ovariectomized rats treated with $F$. umbellata aqueous extract $(200 \mathrm{mg} / \mathrm{kg})$ and MC $(1 \mathrm{mg} / \mathrm{kg})$ showed a significant $(p<$ $0.01)$ reduction in this parameter as compared to OVX rats.

3.5. Effect of 7-Methoxycoumarin and F. umbellata Extract on Anxiety Parameters. It can be observed in Figures 6(a) and 6(c) that ovariectomy induced a significant increase in the number of rearing $(p<0.01)$ and grooming $(p<0.001)$ as compared to normal rats. There was a significant decrease in the number of rearing with piracetam $(p<0.05)$, F. umbellata at the dose of $200 \mathrm{mg} / \mathrm{kg}(p<0.001)$, and MC $(p<0.001)$, 


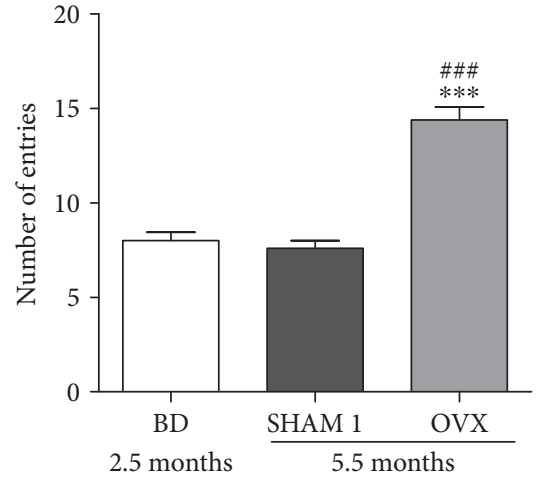

(a)

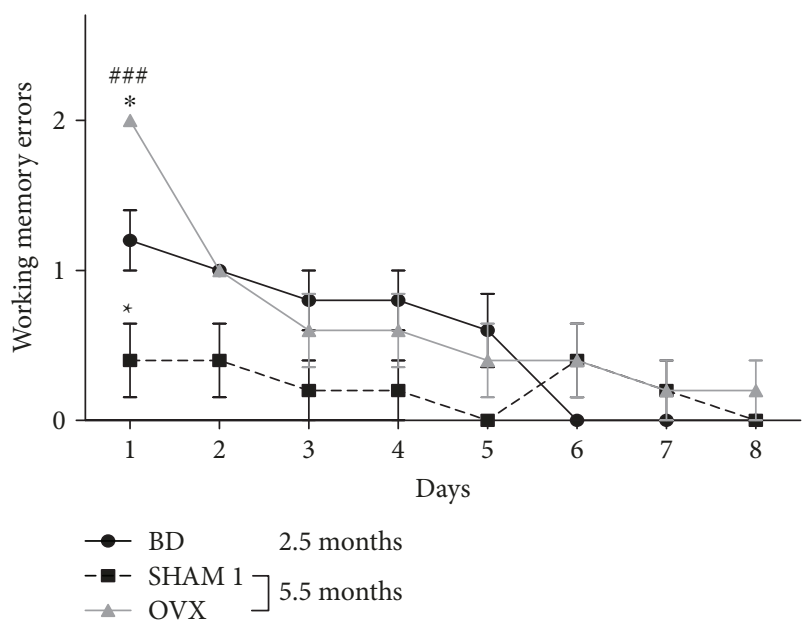

(c)

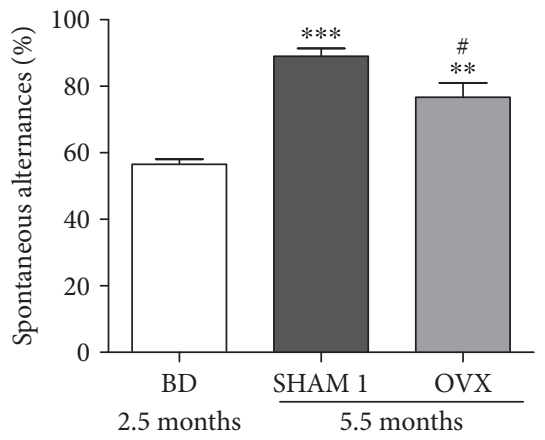

(b)

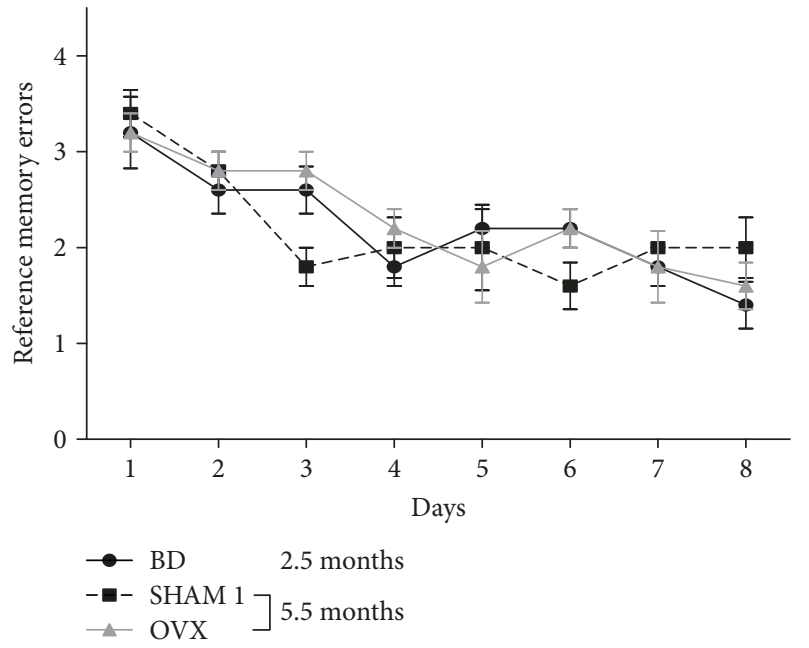

(d)

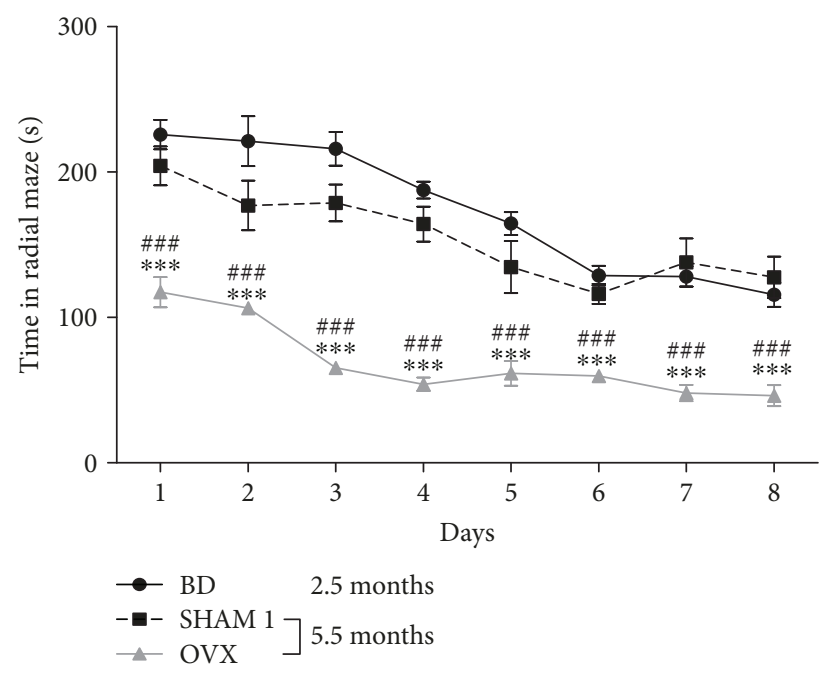

(e)

Figure 2: Effects of age and ovariectomy on number of entries (a), spontaneous alternances (b), working memory (c) and spatial reference memory (d) errors, and the time past in radial maze (e). OVX = ovariectomized rat aged 5.5 months; $\mathrm{BD}=$ nonovariectomized rats aged 2.5 months which served as basic data; SHAM $1=$ nonovariectomized rats aged 5.5 months. ${ }^{*} p<0.05,{ }^{* *} p<0.01$, and ${ }^{* * *} p<0.001$ as compared to control BD. ${ }^{\#} p<0.05$ and ${ }^{\# \# \#} p<0.001$ as compared to the NOR group.

whereas the number of grooming was significantly reduced with piracetam $(p<0.01)$, estradiol $(p<0.001), F$. umbellata $50 \mathrm{mg} / \mathrm{kg}(p<0.001)$ and $200 \mathrm{mg} / \mathrm{kg}(p<0.01)$, and MC $(p<0.01)$ treatment. Following the administration of scopolamine, there was a significant $(p<0.001)$ increase in the number of rearing as well as grooming in normal rats 


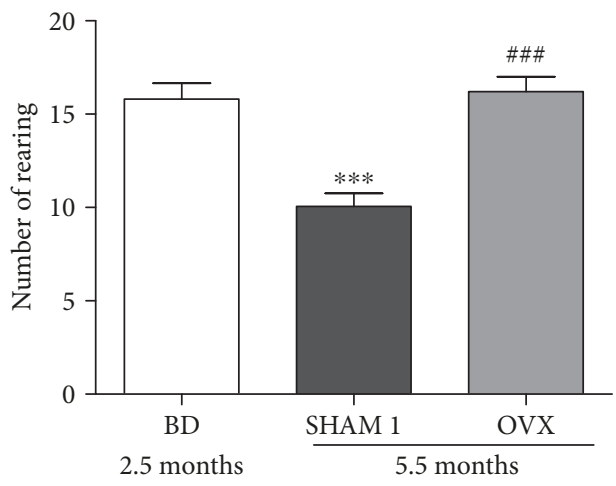

(a)

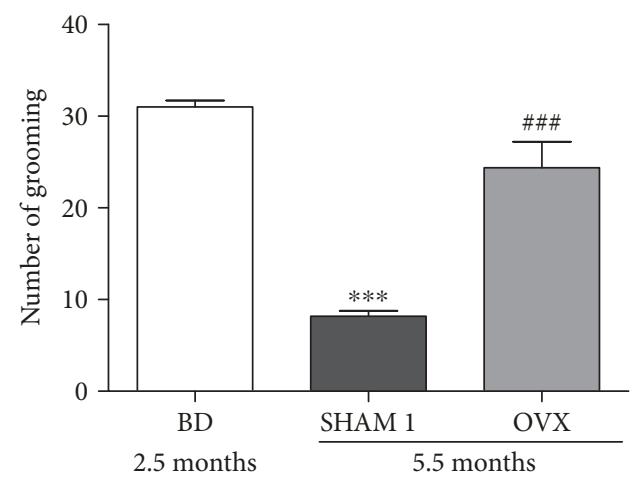

(b)

FIGURE 3: Effects of age and ovariectomy on number of rearing (a) and the number of grooming (b) of rats in the Y-maze. $\mathrm{OVX}=$ ovariectomized rat aged 5.5 months; $\mathrm{BD}=$ nonovariectomized rats aged 2.5 months which served as basic data; SHAM

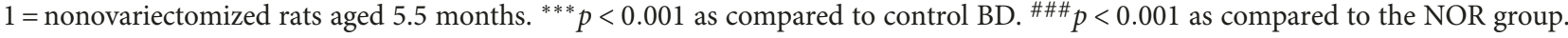

$($ SHAM $2+$ SCOP) and ovariectomized (OVX + SCOP) rats as compared to normal rats (Figures $6(\mathrm{~b})$ and $6(\mathrm{~d})$ ) which did not receive scopolamine (SHAM 1). Piracetam, F. umbellata aqueous extract at all tested doses, and MC significantly decreased the number of rearing and grooming. E2V (1 mg/ $\mathrm{kg}$ ) induced a significant reduction only in the number of grooming as compared to the OVX group.

3.6. Effects on the Weight and the Microarchitecture of the Brain. A significant $(p<0.01)$ decrease in the brain wet weight was observed in ovariectomized rats as compared to normal rats (Figure $7(\mathrm{a})$ ). However, no significant changes were noted following treatment with the different tested substances in this parameter. No alterations in the microarchitecture of hippocampal brain regions were noted in this work (Figure 7(b)).

3.7. Effects on Oxidative Stress Parameters. Figure 8 depicts the effects of treatments on MDA and GSH levels in the brain's homogenate. A decrease in GSH level $(p<0.01)$ and an increase in MDA level $(p<0.05)$ were observed in the OVX group as compared to the sham-operated group following scopolamine administration. All treated groups prevented a decrease in GSH and an increase in MDA, but only the MC group reached statistical significant level $(p<0.05$ for $\mathrm{GSH}$ and $p<0.01$ for MDA).

\section{Discussion}

When women achieve menopause, they are challenged by the effects of estrogen loss on energy, mood, cognitive function, and memory. These stresses are compounded by increased risks for cardiovascular diseases, osteoporosis, cancer, and neurodegenerative diseases [1]. One of the most common diseases among the elderly population is $\mathrm{AD}$, which is classified as a highly complex and progressive neurodegenerative disease [5]. AD is the main cause of dementia worldwide and is characterized by memory decrease and cognitive dysfunction [30]. Two main hypotheses explain the morphological and biochemical changes in AD patients: amyloid and cholinergic hypothesis [31]. The "cholinergic hypothesis" is characterized by a decrease in acetylcholine (ACh) in cholinergic neurons present in the hippocampus and cerebral cortex [32]. The scopolamine-induced memory impairment rat model, which mimics certain aspects of AD-related cognitive impairment and dementia, is based on the cholinergic hypothesis. In fact, scopolamine is a nonselective antagonist of the muscarinic receptor which is capable of blocking cholinergic transmission causing cognitive and memory dysfunction, leading to learning and memory deficits $[26,33]$. Scopolamine-induced AD-like conditions in ovariectomized rats have long been used to demonstrate the neuroprotective effects of xenobiotic substances $[34,35]$. However, none of these studies lasted 84 days after ovariectomy, which is known to be the required time for the setup of postmenopause-like conditions in rats [19-21].

In this study, we demonstrated that subchronic treatment with F. umbellata aqueous extract and 7-methoxycoumarin significantly improved memory and decreased rearing and grooming in scopolamine-demented ovariectomized rats. The Y-maze and the radial arm maze are well-characterized hippocampus-dependent spatial memory tasks used in this study. The Y-maze task is a specific and sensitive test of spatial recognition memory in rodents, which is suitable for evaluating memory as it highlights the ability of rodents to explore a novel environment using their hippocampi mainly $[36,37]$. Short-term memory was then assessed through spontaneous alternation behavior in the Y-maze as previously described $[23,27,38]$. In the first set of tests, the percentage of spontaneous alternations was found to increase with age. Moreover, a 3-month endogenous estrogen depletion following ovariectomy significantly decreased the percentage of spontaneous alternations. These results suggest that rats gaining insurance with age are more stable in the maze. On the other hand, anxiety parameters significantly decreased with age, but increased with ovariectomy in the $\mathrm{Y}$-maze. The aforementioned results suggest that ovariectomy negatively impacts locomotor activity in rats, making them display anxious behavior. Curiously, ovariectomized rats were quite rapid in the collection of baits in the radial maze, but this performance was accompanied with a high number of working memory errors which decreased with habituation. This can be explained by the great appetite that 


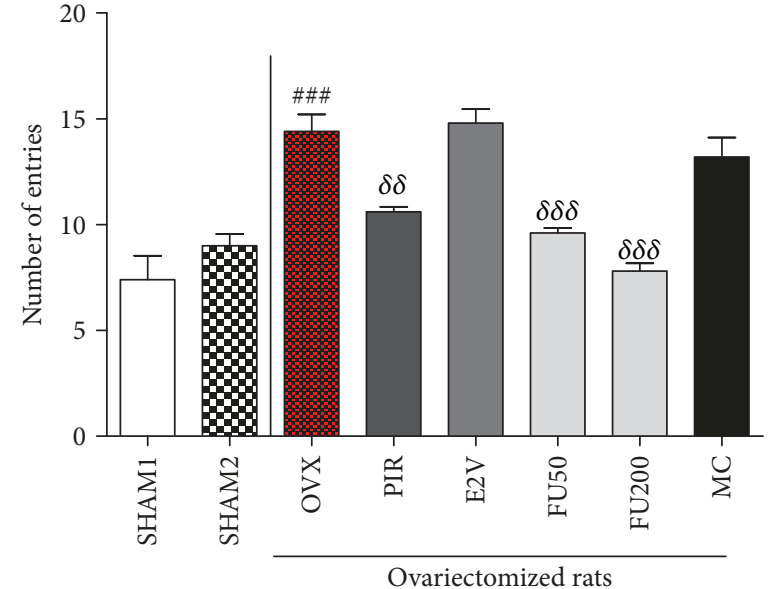

(a)

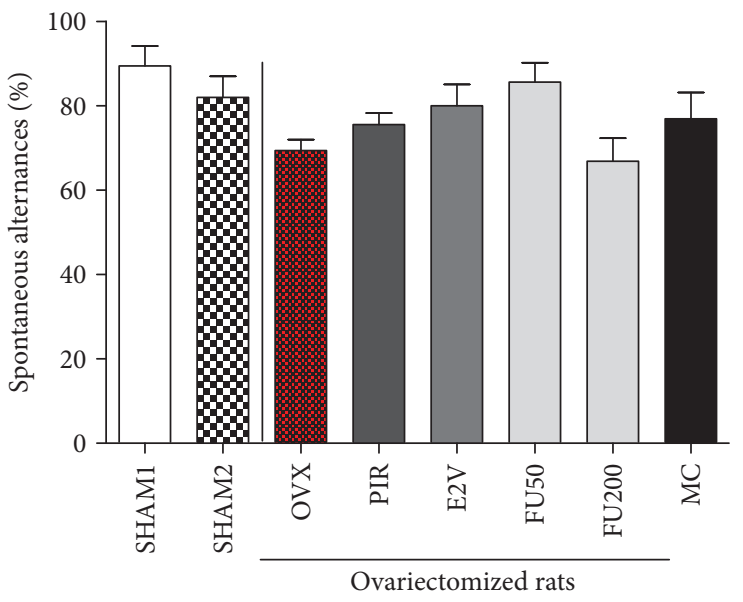

(c)

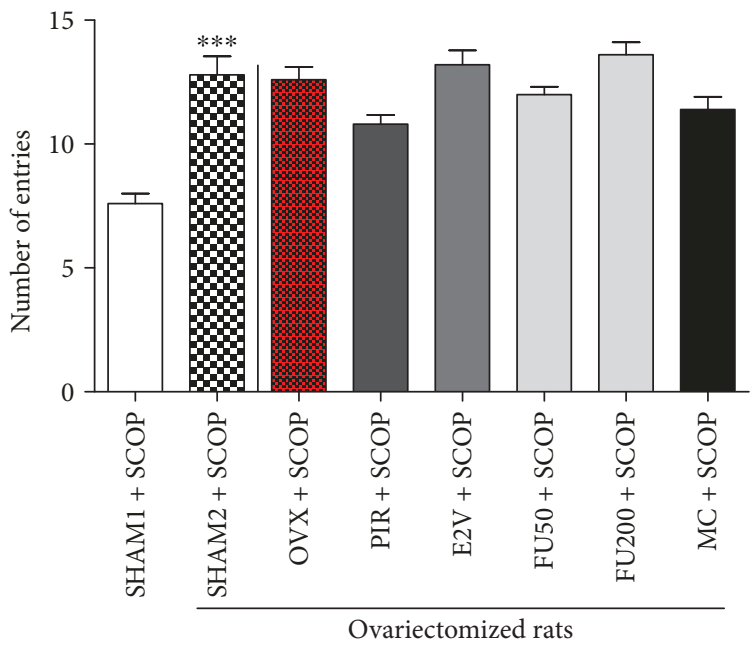

(b)

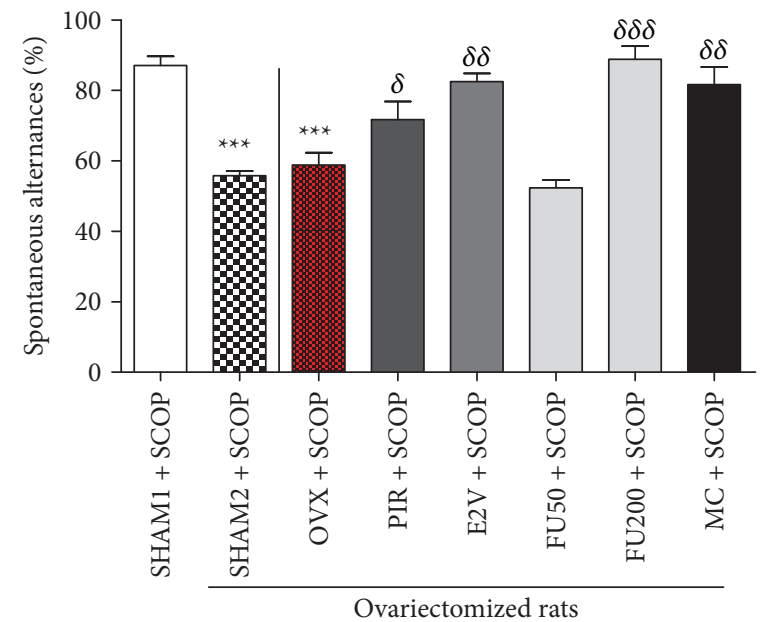

(d)

FIgURE 4: Graphic representation of the number of entries ( $a$ and b) and percentage of spontaneous alternances (c and d) before and after scopolamine exposition in rats treated with different substances into the Y-maze. SHAM $1=$ sham-operated rats treated with vehicle as normal control 1; SHAM 2 = sham-operated rats treated with vehicle as normal control 2; OVX= ovariectomized rats treated with vehicle as negative control; PIR = ovariectomized rats treated with piracetam at the dose of $1.5 \mathrm{mg} / \mathrm{kg}$ BW as positive control 1; $\mathrm{E} 2 \mathrm{~V}=$ ovariectomized rats treated with estradiol valerate at the dose of $1 \mathrm{mg} / \mathrm{kg} \mathrm{BW}$ as positive control 2; FU 50 and $200=$ ovariectomized rats treated with $F$. umbellata aqueous extract at the doses of 50 and $200 \mathrm{mg} / \mathrm{kg} \mathrm{BW}$, respectively; MC= ovariectomized rats treated with 7 -methoxycoumarin at the dose of $1 \mathrm{mg} / \mathrm{kg} \mathrm{BW}$. SCOP = animal that received a single dose of scopolamine $(2 \mathrm{mg} / \mathrm{kg} \mathrm{BW}) .{ }^{* * *} p<0.001$ as compared to the SHAM 1 group; ${ }^{\# \#} p<0.001$ as compared to the SHAM 2 group; ${ }^{\delta} p<0.01,{ }^{\delta} p<0.01$, and ${ }^{\delta \delta} p<0.001$ as compared to the OVX group.

sets up with ovariectomy. These results are consistent with those of Fader et al. [34], who reported that ovariectomy increased the number of working memory errors in the radial arm maze. Studies on both humans and animals indicate that estrogens may also improve memory in women with Alzheimer's disease and reduce the incidence rate of the disease [39]. Moreover, thirty minutes after scopolamine injection, the number of entries increased while the percentage of spontaneous alternations decreased in rats as compared to normal rats which did not receive scopolamine. F. umbellata aqueous extract on the other hand is effective on memory deficits induced by ovariectomy; it loses its promnesic efficacy when ovariectomy is coupled to muscarinic neurotransmission failure. This suggests that the $F$. umbellata extract active components could act upon muscarinic receptors to enhance memory. The failure to do so was due to the presence of scopolamine acting as an antagonist.

The 8-arm radial maze task is widely used in evaluating the effect of drugs, stress, and various other environmental factors on learning and memory [40]. Visual cues set up at 


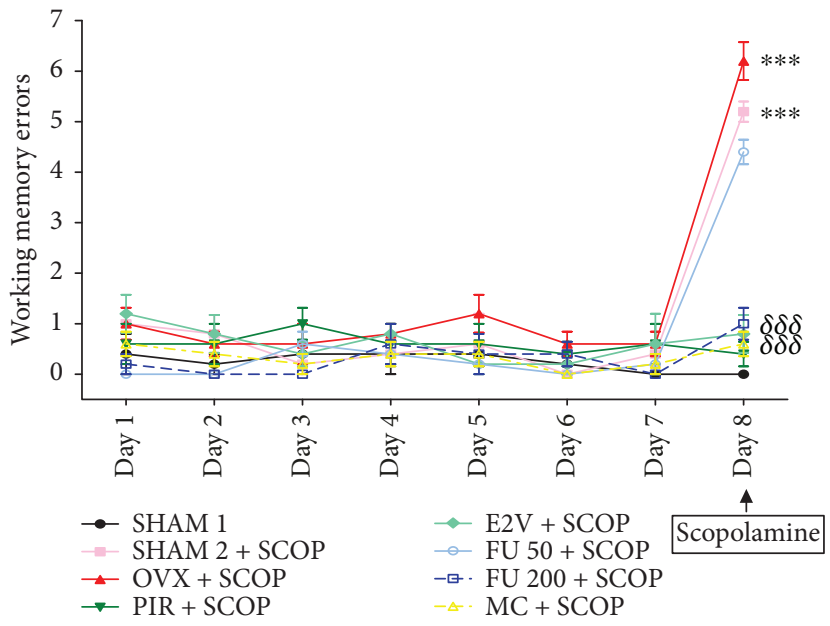

(a)

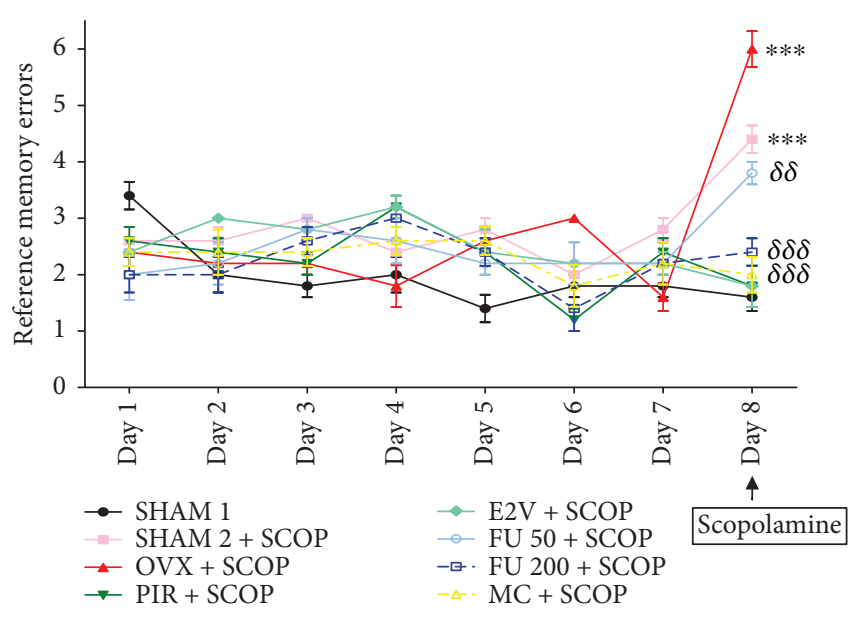

(b)

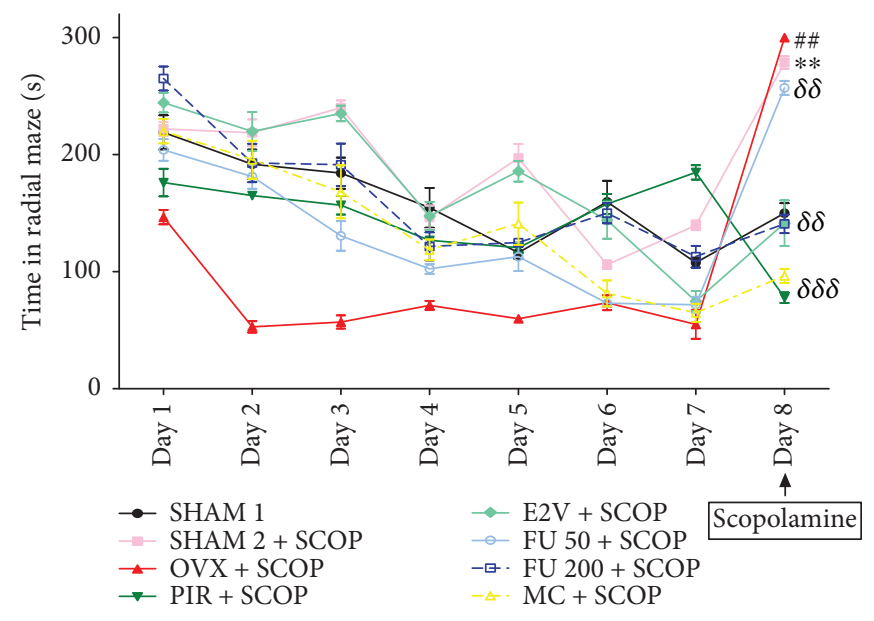

(c)

FIGURE 5: Graphic representation of the working memory (a) and spatial reference memory (b) errors as well as the time past in radial maze (c) before and after scopolamine exposition in rats treated with different substances into the Y-maze. SHAM $1=$ sham-operated rats treated with vehicle as normal control 1; SHAM 2 = sham-operated rats treated with vehicle as normal control 2; OVX= ovariectomized rats treated with vehicle as negative control; PIR = ovariectomized rats treated with piracetam at the dose of $1.5 \mathrm{mg} / \mathrm{kg} \mathrm{BW}$ as positive control 1 ; $\mathrm{E} 2 \mathrm{~V}=$ ovariectomized rats treated with estradiol valerate at the dose of dose $1 \mathrm{mg} / \mathrm{kg} \mathrm{BW}$ as positive control 2; FU 50 and $200=$ ovariectomized rats treated with F. umbellata aqueous extract at the doses of 50 and $200 \mathrm{mg} / \mathrm{kg}$ BW, respectively; $\mathrm{MC}=$ ovariectomized rats treated with 7 -methoxycoumarin at the dose of $1 \mathrm{mg} / \mathrm{kg} \mathrm{BW}$. SCOP=animal that received a single dose of scopolamine $(2 \mathrm{mg} / \mathrm{kg} \mathrm{BW}) .{ }^{* *} p<0.01$ and ${ }^{* * *} p<0.001$ as compared to the SHAM 1 group; \#\# $p<0.01$ as compared to the SHAM 2 group; ${ }^{\delta \delta} p<0.01$ and ${ }^{\delta \delta \delta} p<0.001$ as compared to the OVX group.

the same position throughout the radial maze task acted as spatial references as they are associated with long-term memory and allow the animals to remember the location of the baited arms in the maze. The short-term memory associated with the hippocampus can keep records only for a few seconds to minutes. Memory contents can be transferred, particularly through exercises in the long-term memory $[41,42]$. In the second set of tests, working memory errors significantly reduced with age, whereas ovariectomy increased this parameter. It appears from these results that ovariectomy negatively affects the short-term memory by causing anterograde amnesia [41]. Treatment with $F$. umbellata aqueous extract at the dose of $200 \mathrm{mg} / \mathrm{kg}$ as well as MC at the dose of $1 \mathrm{mg} / \mathrm{kg}$ protected rats against scopolamine-induced memory impairment as evidenced by significantly increased spontaneous alternations, reflecting an improvement in short-term memory. These results suggest that $F$ umbellata and its major compound are endowed with neuroprotective activities given that working memory and reference memory are variables that report the physiological status of the brain [42]. It has been reported that estrogen administered to ovariectomized rats improves working memory performance during acquisition of the radial arm maze task with four arms baited and prevents the disruptive effects of scopolamine on that task [34]; these findings are consistent with ours. The prevention by estrogen of impairments in working memory 


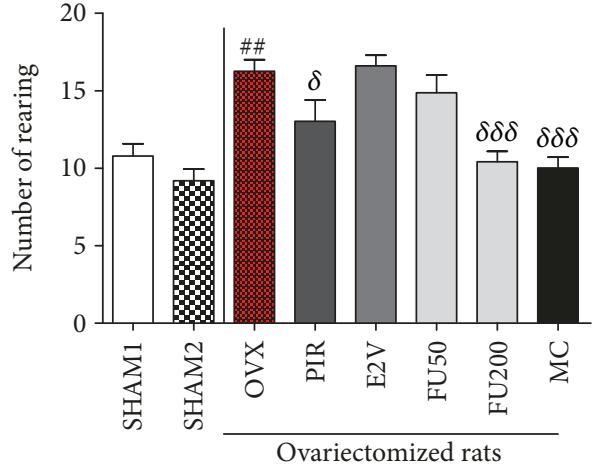

(a)

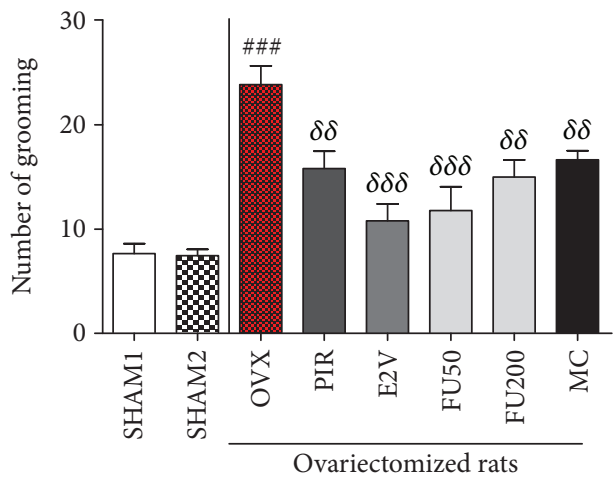

(c)

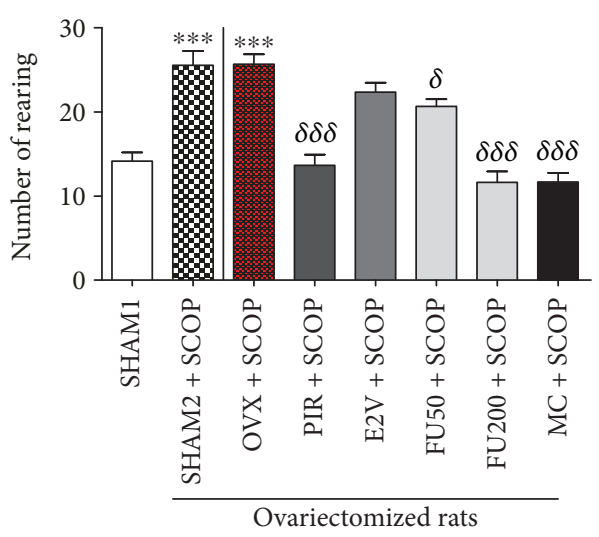

(b)

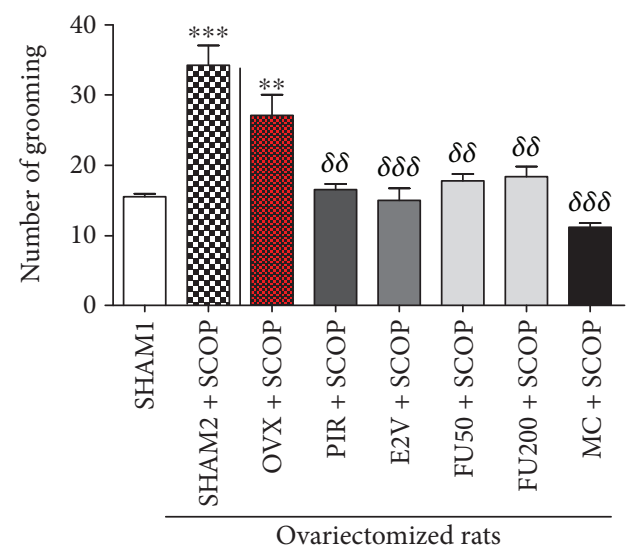

(d)

FiguRE 6: Graphic representation of the number of rearing ( $a$ and b) and grooming ( $c$ and d) of rats in the Y-maze before and after scopolamine exposition in rats treated with different substances into the Y-maze. SHAM 1 = sham-operated rats treated with vehicle as normal control 1; SHAM $2=$ sham-operated rats treated with vehicle as normal control 2; OVX=ovariectomized rats treated with vehicle as negative control; $\mathrm{PIR}=$ ovariectomized rats treated with piracetam at the dose of $1.5 \mathrm{mg} / \mathrm{kg} \mathrm{BW}$ as positive control 1; E2V=ovariectomized rats treated with estradiol valerate at the dose of $1 \mathrm{mg} / \mathrm{kg} \mathrm{BW}$ as positive control 2; FU 50 and $200=$ ovariectomized rats treated with $F$. umbellata aqueous extract at the doses of 50 and $200 \mathrm{mg} / \mathrm{kg} \mathrm{BW}$, respectively; $\mathrm{MC}=$ ovariectomized rats treated with 7-methoxycoumarin at the dose of $1 \mathrm{mg} / \mathrm{kg}$ BW. SCOP $=$ animal that received a single dose of scopolamine $(2 \mathrm{mg} / \mathrm{kg} \mathrm{BW}) .{ }^{* *} p<0.01$ and ${ }^{* * *} p<0.001$ as compared to the SHAM 1 group; ${ }^{\# \#} p<0.01$ and ${ }^{\# \# \#} p<0.001$ as compared to the SHAM 2 group; ${ }^{\delta} p<0.05,{ }^{\delta \delta} p<0.01$, and ${ }^{\delta \delta \delta} p<0.001$ as compared to the OVX group.

performance following scopolamine administration has been attributed to the ability of estrogen to bolster cholinergic functioning in the hippocampus by increasing the activity of choline acetyltransferase [43]. Authors also hypothesized that estrogen may act as growth factors for cholinergic neurons [44] to facilitate reactive fiber growth in hippocampi of ovariectomized rats [45]. Since F. umbellata contains phytoestrogens, it can act like estrogen in hippocampi and then counteract the effects of scopolamine. F. umbellata aqueous extract components could protect rats against memory impairment by binding on estrogen receptors (ER $\alpha$ and $\mathrm{ER} \beta$ ) found in several brain regions including the hippocampus, thereby inhibiting cholinesterase increase induced by scopolamine [46]. The UHPLC-MS performed with this extract revealed that $F$. umbellata contains genistein and biochanin A, well-characterized phytoestrogens [18]. Indeed, previous scientific reports showed that soy isoflavones (daidzein and genistein) improved learning ability and memory of rodents $[47,48]$ as well as humans $[49,50]$. These activities were attributed to the ability of soy isoflavones to mimic the effects of endogenous estrogens through estrogen receptor $\beta$ in the brain [51]. So far, 7-methoxycoumarin failed to transactivate ER $\beta$ such as $F$. umbellata extracts in HEK293T cells stably transfected with ER $\beta$ in a reporter gene assay [17]; it induced its estrogenicity via a nongenomic pathway [18]. The observed neuroprotective effects of $F$. umbellata might be due to the presence of genistein or related chemicals in this plant. Although MC failed to transactivate $\mathrm{ER} \beta$; coumarins are well known as selective inhibitors of acetylcholinesterase $[52,53]$. MC could therefore pass through a nongenomic pathway in the brain to increase acetylcholine concentration, thereby increasing nerve impulses [54]. Anxiety is a parameter that negatively affects learning and memory. The injection of scopolamine helps to accentuate the 


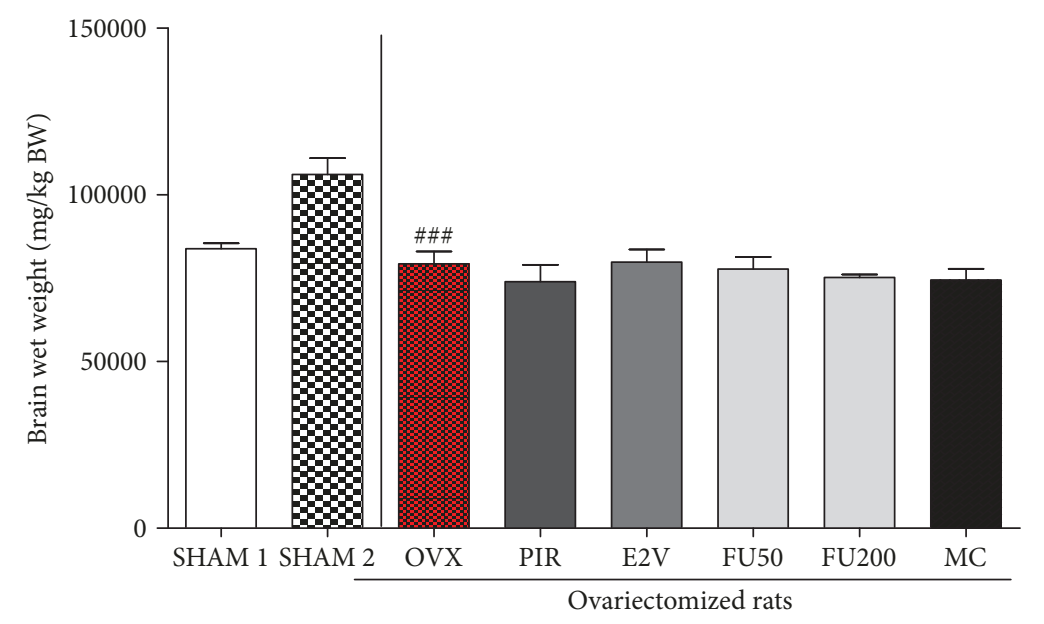

(a)

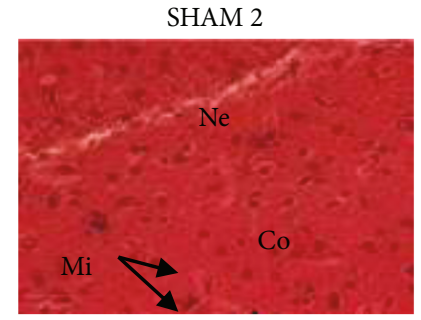

OVX

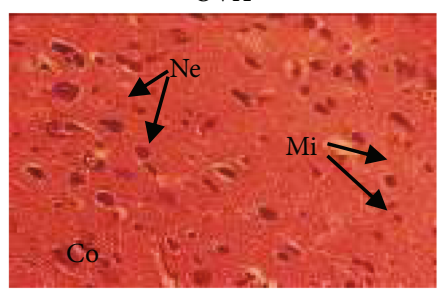

FU 50

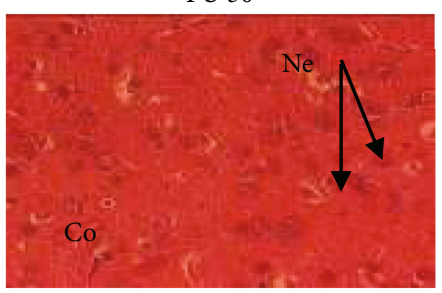

PIR

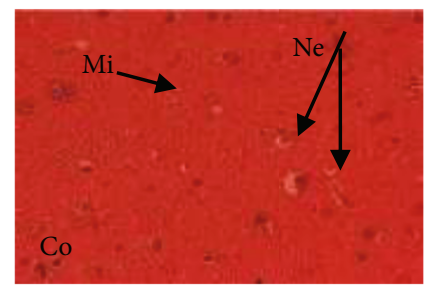

FU 200

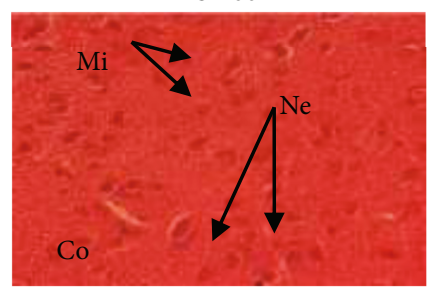

(b)
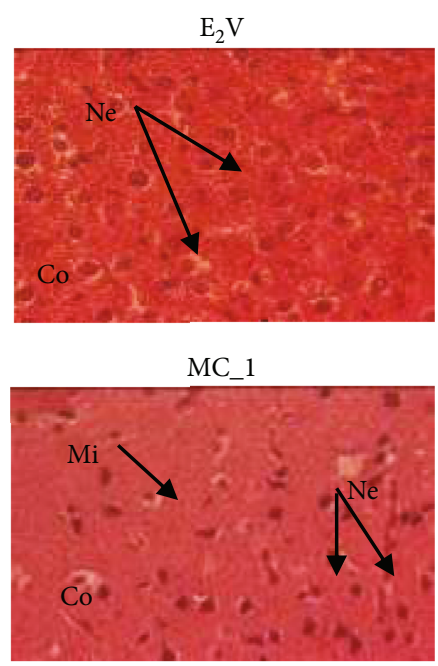

FIGURE 7: Graphical representation of brain wet weight (a) and microphotographs of HE-stained sections (400x) of the hippocampal region of the brain (b) from different experimental rat groups in postmenopause-like conditions after 3 weeks of treatment. SHAM $1=$ shamoperated rats treated with vehicle as normal control 1; SHAM 2=sham-operated rats treated with vehicle as normal control 2; OVX = ovariectomized rats treated with vehicle as negative control; PIR=ovariectomized rats treated with piracetam at the dose of $1.5 \mathrm{mg} / \mathrm{kg} \mathrm{BW}$ as positive control 1; E2V = ovariectomized rats treated with estradiol valerate at the dose of dose $1 \mathrm{mg} / \mathrm{kg} \mathrm{BW}$ as positive control 2; FU 50 and $200=$ ovariectomized rats treated with F. umbellata aqueous extract at the doses of 50 and $200 \mathrm{mg} / \mathrm{kg}$ BW, respectively; $\mathrm{MC}=$ ovariectomized rats treated with 7 -methoxycoumarin at the dose of $1 \mathrm{mg} / \mathrm{kg} \mathrm{BW}$. $\mathrm{Mi}=\mathrm{microg}$ lia; $\mathrm{Ne}=\mathrm{neurons}$; $\mathrm{Co}=$ cortex. ${ }^{\# \# \#} p<0.001$ as compared to SHAM 2 group.

disorder in rats. The treatments with $F$. umbellata aqueous extract at doses of 50 and $200 \mathrm{mg} / \mathrm{kg}$ as well as MC decreased the number of rearing as well as grooming in rats. A chemical messenger widespread in the brain is GABA, which reduces activity of neurons. Some researchers believe that GABA would serve among other things to control the fear or anxiety manifested by neuronal excitation [55]. Scopolamineinduced memory deficits are accompanied with changes in acetylcholinesterase activity [56]. F. umbellata aqueous extract and $\mathrm{MC}$ exhibited anxiolytic properties and act as GABA agonists that bind to receptor GABAergic neurons and modulating the activity of the nervous system [55]. 


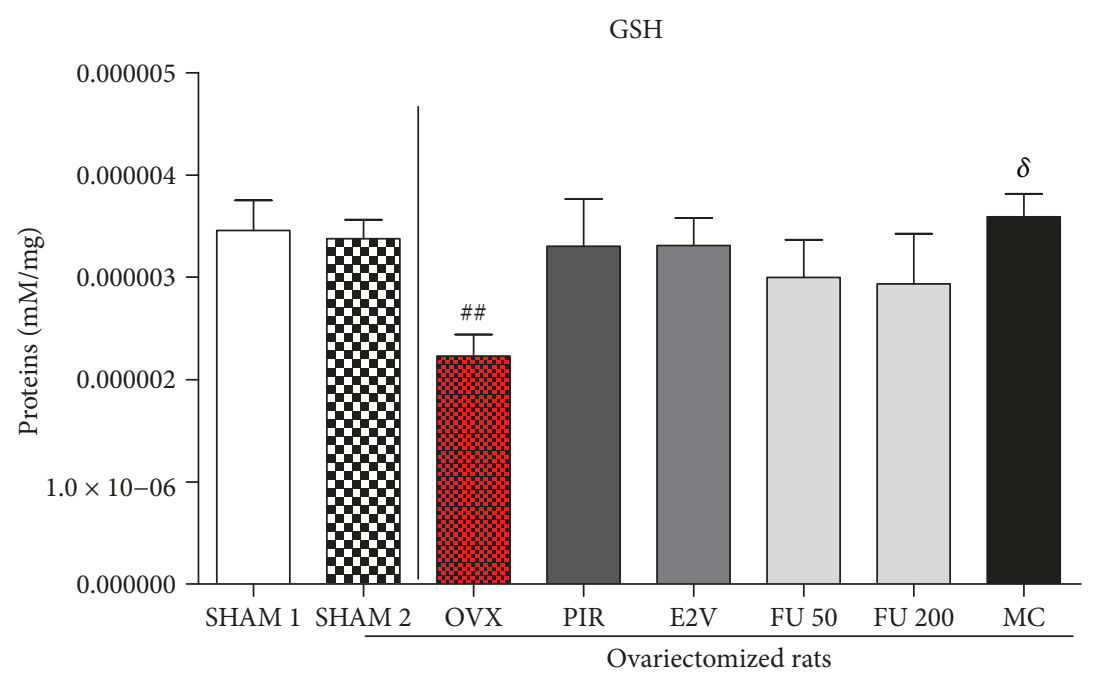

(a)

MDA

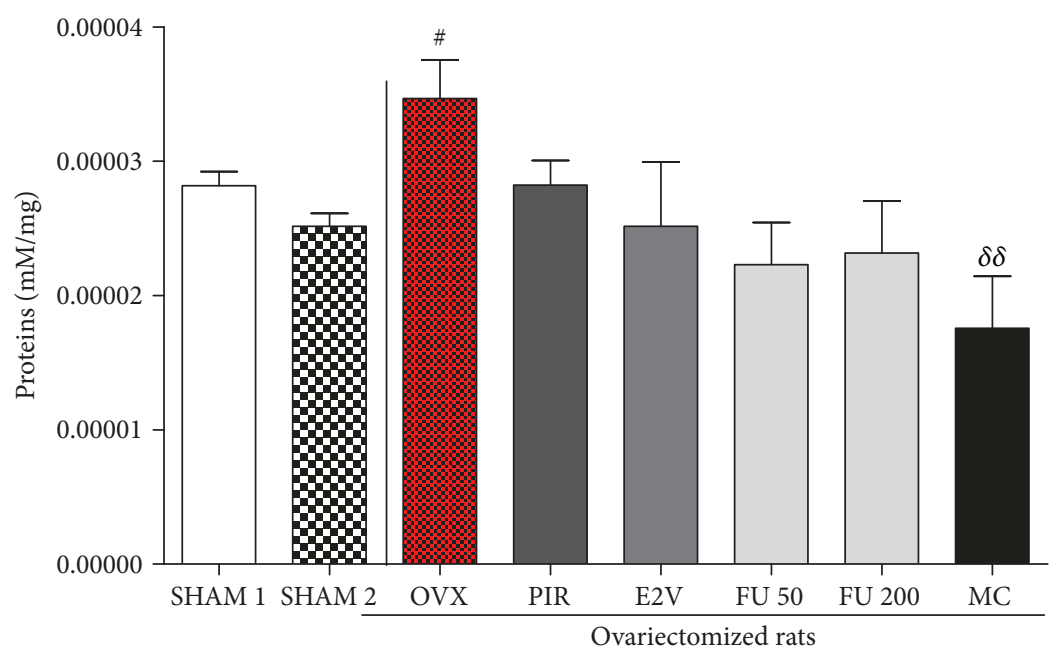

(b)

FIGURE 8: Reduction in glutathione-GSH (a) and malondialdehyde-MDA (b) after scopolamine exposition in rats treated with different substances. SHAM 1 = sham-operated rats treated with vehicle as normal control 1; SHAM $2=$ sham-operated rats treated with vehicle as normal control 2; OVX = ovariectomized rats treated with vehicle as negative control; PIR = ovariectomized rats treated with piracetam at the dose of $1.5 \mathrm{mg} / \mathrm{kg} \mathrm{BW}$ as positive control $1 ; \mathrm{E} 2 \mathrm{~V}=$ ovariectomized rats treated with estradiol valerate at the dose of dose $1 \mathrm{mg} / \mathrm{kg} \mathrm{BW}$ as positive control 2; FU 50 and $200=$ ovariectomized rats treated with $F$. umbellata aqueous extract at the doses of 50 and $200 \mathrm{mg} / \mathrm{kg}$ BW, respectively; $\mathrm{MC}=$ ovariectomized rats treated with 7 -methoxycoumarin at the dose of $1 \mathrm{mg} / \mathrm{kg} \mathrm{BW.}{ }^{\#} p<0.05$ as compared to SHAM 1 ; $\# \# p 0.01$ as compared to the SHAM 2 group; ${ }^{\delta} p<0.05$ and ${ }^{\delta \delta} p<0.01$ as compared to the OVX group.

It is well known that scopolamine-induced memory deficits are accompanied with oxidative damage [57]. A decrease in GSH level and an increase in MDA level in OVX rats were observed after scopolamine administration as compared to sham-operated rats. GSH is an important intracellular radical scavenger, a substrate of many xenobiotic elimination reactions, and participates in the elimination of reactive intermediates by reducing hydroperoxides $[58,59]$. The depletion of GSH levels leads to the increase in oxidative stress. MC prevented the scopolamine-induced accumulation of hydroperoxides by increasing GSH levels. In addition, MDA levels are a lipid peroxidation biomarker. The main target of reactive oxygen species
(ROS) is the polyunsaturated fatty acid in cell membranes. They cause lipid peroxidation and formation of MDA, which may lead to damage of cell structure and function [60]. MC reduced MDA levels as compared to the OVX group in this study. These results suggest a reduction of LDL peroxidation. From this result, the neuroprotective effects of MC may be attributable to its possible antioxidant activity.

\section{Conclusion}

As F. umbellata aqueous extract, 7-methoxycoumarin significantly increased spontaneous alternation and decreased the 
working and spatial reference memory errors, the time taken to collect the baits in the 8-arm radial maze, and the rearing and grooming in ovariectomized rats. Taken altogether, the aforementioned results suggest that 7-methoxycoumarin is endowed with potential neuroprotective effects in rats. In addition, MC showed an antioxidant activity, which could account for its neuroprotective effects. 7-Methoxycoumarin is responsible at least in part for the neuroprotective effects of F. umbellata.

\author{
Abbreviations \\ C-hex: Cyclohexane \\ CPC: Centrifugal partition chromatography \\ DCM: Dichloromethane \\ DMSO: Dimethylsulfoxide \\ ER: Estrogen receptor \\ F: $\quad$ Fraction \\ CNH: Cameroon National Herbarium \\ HPLC: High-performance liquid chromatography \\ MC: 7-Methoxycoumarin \\ $\mathrm{MeOH}$ : Methanol \\ NMR: nuclear magnetic resonance.
}

\section{Ethical Approval}

Housing of animals and all experiments were approved by the Cameroon Institutional National Ethic Committee, which adopted all procedures recommended by the European Union on the protection of animals used for scientific purposes (CEE Council 86/609; reg. no. FWA-IRD 0001954).

\section{Conflicts of Interest}

The authors declare that they have no competing interests.

\section{Authors' Contributions}

Stéphane Zingue, Harquin Simplice Foyet, and Dieudonné Njamen designed the experiments. Stéphane Zingue, Harquin Simplice Foyet, Sefirin Djiogue, Yannick Ezo'o Ezo'o, and Hervé Hervé Ngatanko Abaïssou carried out the in vivo part of the study. Stéphane Zingue, Harquin Simplice Foyet, and Hervé Hervé Ngatanko Abaïssou wrote the manuscript. Dieudonné Njamen supervised the work. All authors read and approved the final manuscript.

\section{Acknowledgments}

Dr. Foyet Harquin Simplice Foyet was supported by The World Academy of Sciences grant (no. 12-132 RG/BIO/ AF/AC_G) and United Nations Educational, Scientific and Cultural Organization FR (12-132 RG/BIO/AF/AC_G of August 2013). The authors also thank Alexander von Humboldt Foundation for the material support offered to Dieudonné Njamen.

\section{Supplementary Materials}

Supplementary Figures AD. (Supplementary Materials)

\section{References}

[1] M.-A. Arevalo, I. Azcoitia, and L. M. Garcia-Segura, "The neuroprotective actions of oestradiol and oestrogen receptors," Neuroscience, vol. 16, no. 1, pp. 17-29, 2015.

[2] I. Azcoitia, C. Fernandez-Galaz, A. Sierra, and L. M. GarciaSegura, "Gonadal hormones affect neuronal vulnerability to excitotoxin-induced degeneration," Journal of Neurocytology, vol. 28, no. 9, pp. 699-710, 1999.

[3] C. R. Overk, P. Y. Lu, Y. T. Wang et al., "Effects of aromatase inhibition versus gonadectomy on hippocampal complex amyloid pathology in triple transgenic mice," Neurobiology of Disease, vol. 45, no. 1, pp. 479-487, 2012.

[4] F. Ding, J. Yao, L. Zhao, Z. Mao, S. Chen, and R. D. Brinton, "Ovariectomy induces a shift in fuel availability and metabolism in the hippocampus of the female transgenic model of familial Alzheimer's," PLoS One, vol. 8, no. 3, article e59825, 2013.

[5] A. S. Morrison and C. Lyketsos, "A review on the pathophysiology of Alzheimers disease and directions in treatment," Advances Study in Nursing, vol. 3, no. 8, pp. 256-270, 2005.

[6] Alzheimer's Disease International (ADI), The Global Impact of Dementia. An Analys of Prevalence, Incidence, Cost and Trends, World Alzheimer Report, London, UK, 2015.

[7] V. Haroutunian, M. Schnaider-Beeri, J. Schmeidler et al., "Role of the neuropathology of Alzheimer disease in dementia in the oldest-old," Archives of Neurology, vol. 65, no. 9, pp. 1211-1217, 2008.

[8] Alzheimer's Association, "2015 Alzheimer's disease facts and figures,” Alzheimer's \& Dementia, vol. 11, no. 3, pp. 332-384, 2015.

[9] E. Scott, Q. G. Zhang, R. Wang, R. Vadlamudi, and D. Brann, "Estrogen neuroprotection and the critical period hypothesis," Frontiers in Neuroendocrinology, vol. 33, no. 1, pp. 85-104, 2012.

[10] B. B. Sherwin, "Estrogen and cognitive functioning in women," Endocrine Reviews, vol. 24, no. 2, pp. 133-151, 2003.

[11] J. E. Rossouw, G. L. Anderson, R. L. Prentice et al., "Risks and benefits of estrogen plus progestin in healthy postmenopausal women: principal results from the Women's Health Initiative randomized controlled trial," Journal of the American Medical Association, vol. 288, no. 3, pp. 321-333, 2002.

[12] Million Women Study Collaborators, "Breast cancer and hormone-replacement therapy in the Million Women Study," The Lancet, vol. 362, no. 9382, pp. 419-427, 2003.

[13] Million Women Study Collaborators, "Endometrial cancer and hormone-replacement therapy in the Million Women Study," The Lancet, vol. 365, no. 9470, pp. 1543-1551, 2005.

[14] J. Pitkin, "Alternative and complementary therapies for the menopause," Menopause International, vol. 18, no. 1, pp. 20 27, 2012.

[15] M. Arbonnier, Arbres, arbustes et lianes des zones sèches d'Afrique de l'Ouest, 2009, Editions Quæ RD 10; F- 78026 Versailles Cedex, France; Muséum National d'histoire Naturelle (MNHN) ; Service des publications scientifiques, 57 Rue Cuvier, F-75005 Paris, France.

[16] K. Babu, S. G. Shankar, and S. Rai, "Comparative pharmacognostic studies on the barks of four Ficus species," Turkish Journal of Botany, vol. 34, no. 3, pp. 215-224, 2010. 
[17] S. Zingue, T. Michel, J. Tchatchou et al., "Estrogenic effects of Ficus umbellata Vahl. (Moraceae) extracts and their ability to alleviate some menopausal symptoms induced by ovariectomy in Wistar rats," Journal of Ethnopharmacology, vol. 179, no. 1, pp. 332-344, 2016.

[18] S. Zingue, T. Michel, C. B. M. Nde et al., "Estrogen-like and tissue-selective effects of 7-methoxycoumarin from Ficus umbellata (Moraceae): an in vitro and in vivo study," $B M C$ Complementary and Alternative Medicine, vol. 17, no. 1, pp. 383-396, 2017.

[19] D. Njamen, C. B. Magne Ndé, Z. Tanee Fomum, and J. C. Mbanya, "Preventive effects of an extract of Erythrina Lysistemon (Fabaceae) on some menopausal problems: studies on the rat," Journal of Complementary and Integrative Medicine, vol. 4, no. 1, 2007.

[20] M. E. Basha, S. Chang, L. J. Burrows et al., "Effect of estrogen on molecular and functional characteristics of the rodent vaginal muscularis," The Journal of Sexual Medicine, vol. 10, no. 5, pp. 1219-1230, 2013.

[21] D. D. Paul Désiré, M. N. Yolande Sandrine, B. Danielle Claude et al., "In vivo estrogenic-like activities of Gouania longipetala Hemsl. (Rhamnaceae) bark extracts in a post-menopause-like model of ovariectomized Wistar rats," Journal of Ethnopharmacology, vol. 168, no. 1, pp. 122-128, 2015.

[22] R. J. Wurtman, S. G. Magil, and D. K. Reinstein, "Piracetam diminishes hippocampal acetylcholine levels in rats," Life Sciences, vol. 28, no. 10, pp. 1091-1093, 1981.

[23] H. S. Foyet, H. H. Ngatanko Abaïssou, E. Wado, E. Asongalem Acha, and C. Alin, "Emilia coccinae (SIMS) G extract improves memory impairment, cholinergic dysfunction, and oxidative stress damage in scopolamine-treated rats," $B M C$ Complementary and Alternative Medicine, vol. 15, no. 1, 2015.

[24] N. G. Hernández-Chan, J. L. Góngora-Alfaro, F. J. ÁlvarezCervera, F. A. Solís-Rodríguez, F. J. Heredia-López, and G. Arankowsky-Sandoval, "Quinolinic acid lesions of the pedunculopontine nucleus impair sleep architecture, but not locomotion, exploration, emotionality or working memory in the rat," Behavioural Brain Research, vol. 225, no. 2, pp. 482490, 2011.

[25] M. D. S. Lapiz-Bluhm, C. O. Bondi, J. Doyen, G. A. Rodriguez, T. Bédard-Arana, and D. A. Morilak, "Behavioural assays to model 'cognitive and affective dimensions of depression and anxiety in rats," Journal of Neuroendocrinology, vol. 20, no. 10, pp. 1115-1137, 2008.

[26] L. Hritcu, O. Cioanca, and M. Hancianu, "Effects of lavender oil inhalation on improving scopolamine-induced spatial memory impairment in laboratory rats," Phytomedicine, vol. 19, no. 6, pp. 529-534, 2012.

[27] G. J. Beppe, A. B. Dongmo, H. S. Foyet et al., "Memoryenhancing activities of the aqueous extract of Albizia adianthifolia leaves in the 6-hydroxydopamine-lesion rodent model of Parkinson's disease," BMC Complementary and Alternative Medicine, vol. 14, no. 1, 2014.

[28] M. Shamnas, R. Ratendra, and U. V. S. Teotia, "Neuroprotective activity of methanol extract of Salvia officinalis flowers in dementia related to Alzheimer disease," Der Pharmacia Sinica, vol. 5, no. 2, pp. 29-38, 2014.

[29] M. Padurariu, A. Ciobica, L. Hritcu, B. Stoica, W. Bild, and C. Stefanescu, "Changes of some oxidative stress markers in the serum of patients with mild cognitive impairment and Alzheimer's disease," Neuroscience Letters, vol. 469, no. 1, pp. 6-10, 2010.
[30] N. Cortes, R. Alvarez, E. H. Osorio, F. Alzate, S. Berkov, and E. Osorio, "Alkaloid metabolite profiles by GC/MS and acetylcholinesterase inhibitory activities with binding-mode predictions of five Amaryllidaceae plants," Journal of Pharmaceutical and Biomedical Analysis, vol. 102, pp. 222-228, 2015.

[31] A. Contestabile, "The history of the cholinergic hypothesis," Behavioural Brain Research, vol. 221, no. 2, pp. 334-340, 2011.

[32] D. K. Lahiri, M. R. Farlow, N. H. Greig, and K. Sambamurti, "Current drug targets for Alzheimer's disease treatment," Drug Development Research, vol. 56, no. 3, pp. 267-281, 2002.

[33] A. C. G. Souza, C. A. Bruning, C. I. Acker, J. S. S. Neto, and C. W. Nogueira, "2-Phenylethynyl-butyltellurium enhances learning and memory impaired by scopolamine in mice," Behavioural Pharmacology, vol. 24, no. 4, pp. 249-254, 2013.

[34] A. J. Fader, P. E. M. Johnson, and G. P. Dohanich, "Estrogen improves working but not reference memory and prevents amnestic effects of scopolamine on a radial-arm maze," Pharmacology Biochemistry and Behavior, vol. 62, no. 4, pp. 711717, 1999.

[35] S. M. R. Wahba, A. S. Darwish, and S. M. Kamal, "Ceriacontaining uncoated and coated hydroxyapatite-based galantamine nanocomposites for formidable treatment of Alzheimer's disease in ovariectomized albino-rat model," Materials Science and Engineering C, vol. 65, no. 1, pp. 151-163, 2016.

[36] Y. Sadiq, A. B. Alexander, and A. Abdulkarim, "Effect of Ziziphus mauritiania (L.) seed extracts on spatial recognition memory of rats as measured by the Y-maze test," Journal of Natural Products, vol. 2, no. 1, pp. 31-39, 2009.

[37] M. Bagheri, M.-T. Joghataei, S. Mohseni, and M. Roghani, "Genistein ameliorates learning and memory deficits in amyloid $\beta$ (1-40) rat model of Alzheimer's disease," Neurobiology of Learning and Memory, vol. 95, no. 3, pp. 270-276, 2011.

[38] H. E. Jing, Y.-m. CHEN, J.-h. WANG, and M. A. Yuan-ye, "Effect of co-administration of morphine and cholinergic antagonists on Y-maze spatial recognition memory retrieval and locomotor activity in mice," Zoological Research, vol. 29, no. 6, pp. 613-620, 2008.

[39] M.-X. Tang, D. Jacobs, Y. Stern et al., "Effect of oestrogen during menopause on risk and age at onset of Alzheimer's disease," Lancet, vol. 348, no. 9025, pp. 429-432, 1996.

[40] M. Mizuno, K. Yamada, A. Olariu, H. Nawa, and T. Nabeshima, "Involvement of brain-derived neurotrophic factor in spatial memory formation and maintenance in a radial arm maze test in rats," Journal of Neuroscience, vol. 20, no. 18, pp. 7116-7121, 2000.

[41] T. Myhrer, "Neurotransmitter systems involved in learning and memory in the rat: a meta-analysis based on studies of four behavioral tasks," Brain Research Reviews, vol. 41, no. 23, pp. 268-287, 2003.

[42] A. D. J. Titus, B. S. Shankaranarayana Rao, H. N. Harsha et al., "Hypobaric hypoxia-induced dendritic atrophy of hippocampal neurons is associated with cognitive impairment in adult rats," Neuroscience, vol. 145, no. 1, pp. 265-278, 2007.

[43] M. Singh, E. M. Meyer, W. J. Millard, and J. W. Simpkins, "Ovarian steroid deprivation results in a reversible learning impairment and compromised cholinergic function in female Sprague-Dawley rats," Brain Research, vol. 644, no. 2, pp. 305312, 1994.

[44] H. Honjo, T. Tamura, Y. Matsumoto et al., "Estrogen as a growth factor to central nervous cells," The Journal of Steroid 
Biochemistry and Molecular Biology, vol. 41, no. 3-8, pp. 633635, 1992.

[45] S. W. Scheff, J. K. Morse, and S. T. DeKosky, "Neurotrophic effects of steroids on lesion-induced growth in the hippocampus. I. The asteroidal condition," Brain Research, vol. 457, no. 2, pp. 246-250, 1988.

[46] M. Hosseini, T. Mohammadpour, R. Karami, Z. Rajaei, H. Reza Sadeghnia, and M. Soukhtanloo, "Effects of the hydro-alcoholic extract of Nigella sativa on scopolamineinduced spatial memory impairment in rats and its possible mechanism," Chinese Journal of Integrative Medicine, vol. 21, no. 6, pp. 438-444, 2015.

[47] A. M. Duncan, W. R. Phipps, and M. S. Kurzer, "Phyto-oestrogens," Best Practice \& Research Clinical Endocrinology \& Metabolism, vol. 17, no. 2, pp. 253-271, 2003.

[48] Y. H. Huang, X. Y. Xin, and Y. Q. Chen, "Effects of genistein and $17 \beta$ estradiol on the spatial learning and memory in ovariecomized rats," Journal of Fourth Military Medical University, vol. 25, no. 1, pp. 46-49, 2004.

[49] S. File, N. Jarrett, E. Fluck, R. Duffy, K. Casey, and H. Wiseman, "Eating soya improves human memory," Psychopharmacology, vol. 157, no. 4, pp. 430-436, 2001.

[50] L. Zhao and R. D. Brinton, "WHI and WHIMS follow-up and human studies of soy isoflavones on cognition," Expert Review of Neurotherapeutics, vol. 7, no. 11, pp. 1549-1564, 2007.

[51] Y. B. Lee, H. J. Lee, and H. S. Sohn, "Soy isoflavones and cognitive function," The Journal of Nutritional Biochemistry, vol. 16, no. 11, pp. 641-649, 2005.

[52] F. Leonetti, M. Catto, O. Nicolotti et al., "Homo- and heterobivalent edrophonium-like ammonium salts as highly potent, dual binding site AChE inhibitors," Bioorganic \& Medicinal Chemistry, vol. 16, no. 15, pp. 7450-7456, 2008.

[53] L. G. de Souza, M. N. Rennó, and J. D. Figueroa-Villar, "Coumarins as cholinesterase inhibitors: a review," ChemicoBiological Interactions, vol. 254, no. 1, pp. 11-23, 2016.

[54] X.-M. Peng, G. L. V. Damu, and C. H. Zhou, "Current developments of coumarin compounds in medicinal chemistry," Current Pharmaceutical Design, vol. 19, no. 21, pp. 3884-3930, 2013.

[55] I. Gauthier and P. Nuss, "Anxiety disorders and GABA neurotransmission: a disturbance of modulation," Neuropsychiatric Disease and Treatment, 2015.

[56] R. Kaur, S. Parveen, S. Mehan, D. Khanna, and S. Kalra, "Neuroprotective effect of Ellagic acid against chronically scopolamine induced Alzheimer's type memory and cognitive dysfunctions: possible behavioural and biochemical evidences," International Journal of Preventive Medicine, vol. 1, no. 2, pp. 45-64, 2015.

[57] Y. K. Lee, D. Y. Yuk, T. I. Kim et al., "Protective effect of the ethanol extract of Magnolia officinalis and 4-Omethylhonokiol on scopolamine-induced memory impairment and the inhibition of acetylcholinesterase activity," Journal of Natural Medicines, vol. 63, no. 3, pp. 274-282, 2009.

[58] Z. Gregus, T. Fekete, E. Halaszi, and C. D. Klaassen, "Lipoic acid impairs glycine conjugation of benzoic acid and renal excretion of benzoylglycine," Drug Metabolism and Disposition, vol. 24, no. 6, pp. 682-688, 1996.
[59] P. Nicotera and S. Orrenius, "Role of thiols in protection against biological reactive intermediates," Advances in Experimental Medicine and Biology, 1986.

[60] H. Kuper, A. Tzonou, E. Kaklamani et al., "Tobacco smoking alcohol consumption and their interaction in the causation of hepatocellular carcinoma," International Journal of Cancer, vol. 85, no. 4, pp. 498-502, 2000. 


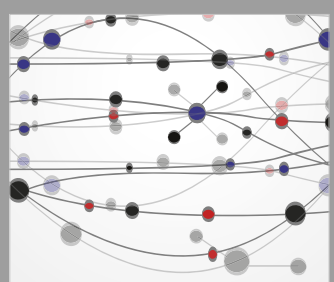

The Scientific World Journal
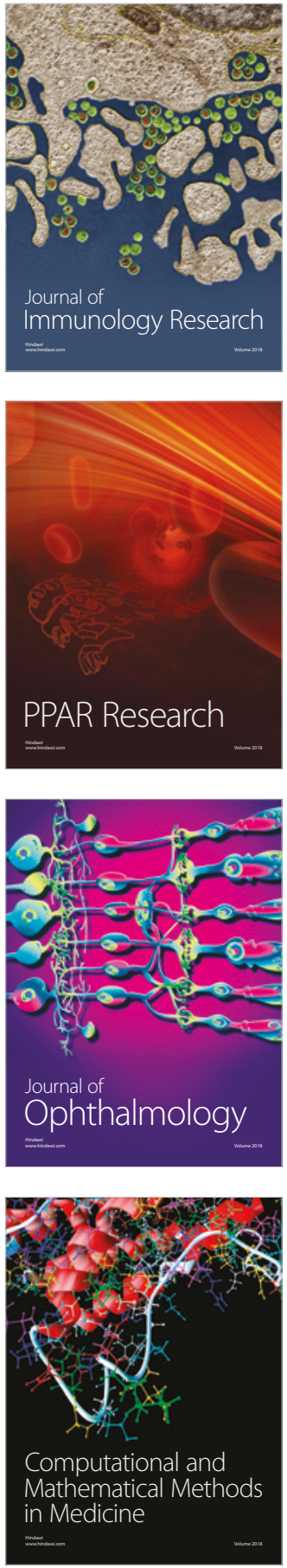

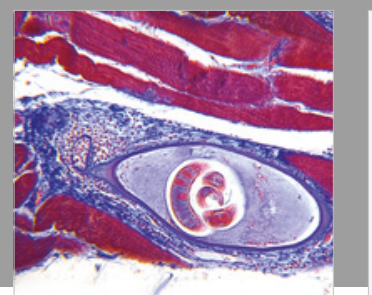

Gastroenterology Research and Practice

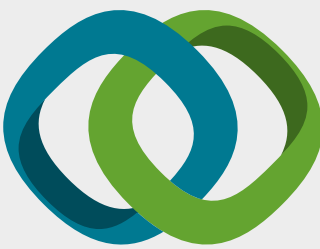

\section{Hindawi}

Submit your manuscripts at

www.hindawi.com
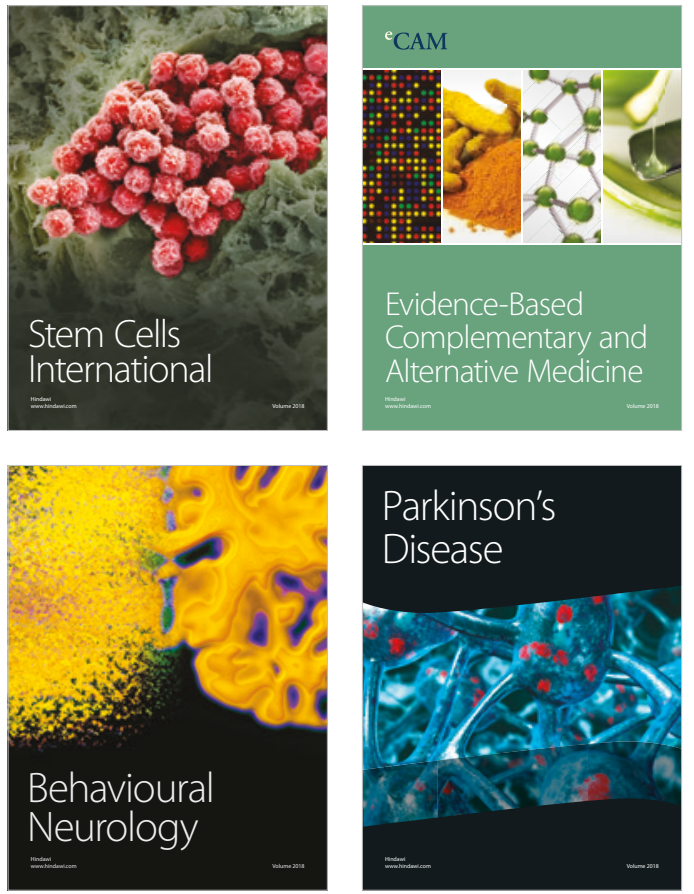

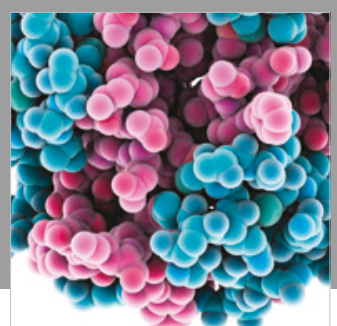

ournal of

Diabetes Research

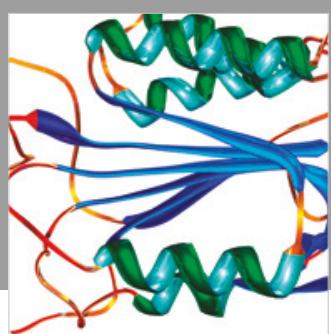

Disease Markers
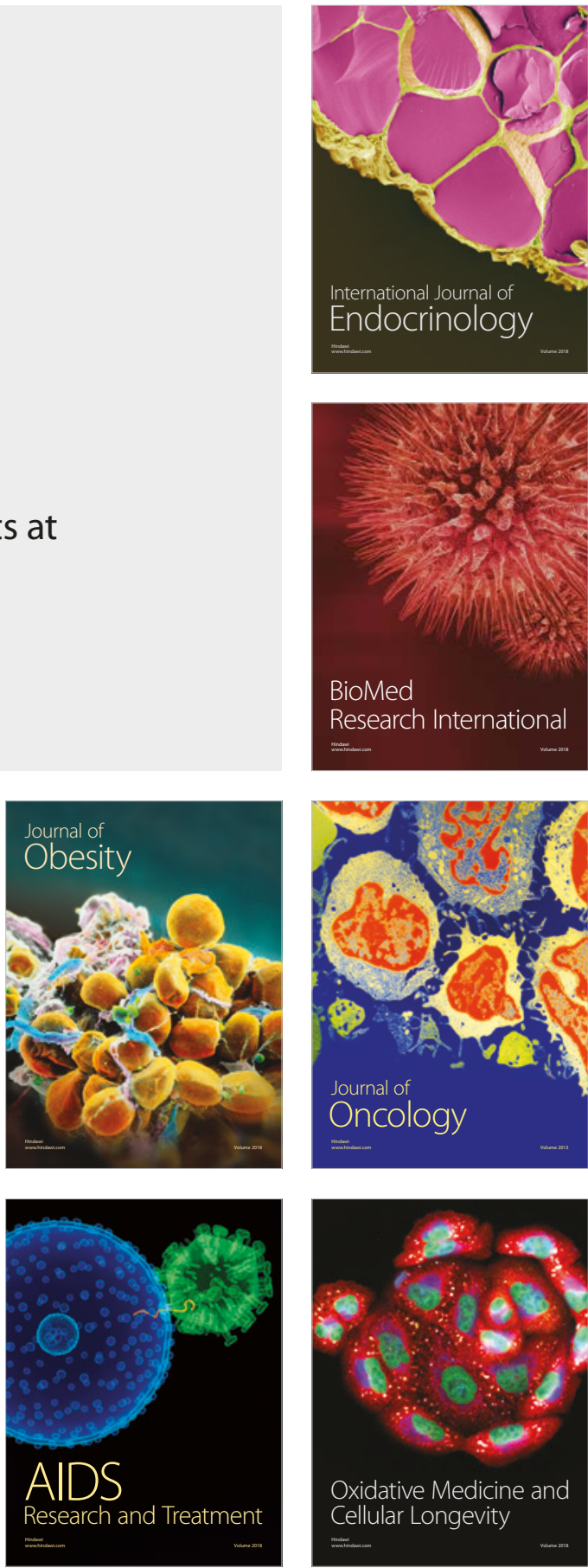